\title{
Combined treatment of eCG and a non-selective inhibitor of phosphodiesterases for enhancing reproductive performance in ewes
}

\author{
Irene Valasi ${ }^{1,4}$, Ekaterini K. Theodosiadou ${ }^{1}$, Serafeim Papadopoulos ${ }^{2}$, Mariana S. Barbagianni ${ }^{1}$, Apostolos \\ Nanos $^{1}$, Stavros Spanos ${ }^{1}$, Georgios C. Fthenakis ${ }^{1}$, Stella Chadio ${ }^{3}$ \\ ${ }^{1}$ Veterinary Faculty, University of Thessaly, Karditsa, Greece. \\ ${ }^{2}$ Department of Animal Production, Technological Educational Institute of Larissa, Larissa, Greece. \\ ${ }^{3}$ Faculty of Animal Science and Aquaculture, Agricultural University of Athens, Athens, Greece.
}

\begin{abstract}
The aim of this study was to evaluate the effect of the non-selective phosphodiesterase inhibitor 3isobutyl-1-methyl-xanthine (IBMX) given concomitantly with eCG on reproductive performance of ewes. In trial 1 , eighty ewes were allocated into 8 groups (AC, A1, A2, A3 and DC, D1, D2, D3). Oestruses were synchronized by progestagen sponges. At sponges removal all ewes of A groups received 400 IU of eCG. Concomitantly with eCG, ewes of groups $\mathrm{A} 1, \mathrm{~A} 2$ or $\mathrm{A} 3$ received IMBX at the dose of 2.5, 5.0 or $25.0 \mathrm{mg}$, respectively. Ewes of D1, D2 or D3 groups received only IBMX at the same doses, respectively; in each case, ewes of AC or DC groups were controls (C). In trial 2, one hundred eighteen ewes were allocated into 4 groups (BC1, B1 and $\mathrm{BC} 2, \mathrm{~B} 2)$. Oestruses were synchronized by progestagen sponges. At sponges removal ewes of $\mathrm{BC} 1$ or $\mathrm{B} 1$ received $200 \mathrm{IU}$ of eCG, while ewes of $\mathrm{BC} 2$ or $\mathrm{B} 2$ groups received $100 \mathrm{IU}$. At the same time only ewes of B1 or B2 groups received $2.5 \mathrm{mg}$ IBMX. In both trials, 48 hours after hormonal treatment, ewes were mated. In trial 1 , pregnancy or lambing rate did not differ among A or D groups $(\mathrm{P}>0.05)$. Total lambs per ewe were significantly higher in A1 compared to AC, A2, A3 or D1 groups $(\mathrm{P}<0.05)$, but did not differ among $\mathrm{D}$ groups $(\mathrm{P}>0.05)$. In trial 2 , pregnancy or lambing rate did not differ among $\mathrm{B}$ groups $(\mathrm{P}>0.05)$. Total lambs per ewe were significantly higher $(\mathrm{P}<0.05)$ in $\mathrm{B} 1$ and $\mathrm{B} 2$ compared to $\mathrm{BC} 1$ and $\mathrm{BC} 2$ groups, respectively. These results indicate that IBMX combined with eCG at the end of an oestrus synchronization treatment improves litter size probably by increasing ovulation rate in ewes. This latter effect seems to be mainly dependent on the amount of gonadotrophins used.
\end{abstract}

Keywords: eCG, ewes, IBMX, litter size, pregnancy rate.

\section{Introduction}

Pharmaceutical control of sheep reproduction usually involves the administration of hormones or analogues related to oestrous cycle, such as progesterone, prostaglandins, and/or melatonin (Abecia et al., 2012). Equine chorionic gonadotrophin (eCG) is used commonly in sheep hormonal treatment protocols (Bister et al., 1999; Maurel et al., 2003; Abecia et al., 2011; 2012). It has FSH- and LH-like activity (Bister et al., 1999; Abecia et al., 2012), as a result of which it affects number of selected and dominant follicles, preovulatory LH surge and, thus, ovulation rate. However, its use has been associated with various adverse effects (e.g. low pregnancy rate, immunogenic action, follicular cysts formation, early corpora lutea regression) (Maurel et al., 2003; Menchaca and Rubianes, 2004). Thus, there is a need to evaluate alternative substances for improvement of reproductive control protocols.

Phosphodiesterases (PDEs) appear to have a catalytic activity in many cellular functions including mediation of the gonadotrophin actions on the ovarian cells. Different PDEs can share the same catalytic function, although differing in tissue expression and intracellular localization. To date, twelve PDE gene families have been identified (Levy et al., 2011).

$$
\text { The non-selective inhibitor of }
$$

phosphodiesterases, the 3-isobutyl-1-methyl-xanthine (IBMX), is a broad-spectrum PDE inhibitor, as it inhibits all PDE families, except PDE8 and PDE9 (Conti and Beavo, 2007). An in vitro study performed in sheep showed improvement of embryo quality after use of forskolin and IBMX, in comparison to use of standard IVM methods (Rose et al., 2013). Administration of IBMX in gonadotrophin- or GnRH-treated nulliparous young doe-rabbits increased pregnancy rate and birth rate, litter size and litter weight (Sirotkin et al., 2010a), as well as offspring viability after birth (Balazi et al., 2012); both studies showed increase in ovulations/corpora lutea, zygotes and embryos. Synthetic PDE4 inhibitors increased number of ovulations and pups born from hCG-stimulated rats (McKenna et al., 2005); hCG and PDE4 inhibitor acted synergistically to enhance ovulation response.

Use of GnRH has already been attempted with variable results (Ménchaca and Rubianes, 2004; Deligiannis et al., 2005). It has been demonstrated that $\mathrm{GnRH}$ can increase numbers of $\mathrm{LH} / \mathrm{hCG}$ receptors in granulosa cells, while activation of ovarian cell function is mediated via cAMP- and/or cGMP-dependent intracellular mechanisms (Sirotkin et al., 1994). Both cyclic nucleotides are hydrolyzed by PDEs (Greco and Stabenfeldt, 2007). Increased accumulation of cyclic nucleotides could promote action of GnRH and gonadotropins at the ovary, thus affecting folliculogenesis, oogenesis, number and quality of gametes and ovarian or upstream hormones (Sirotkin et al., 1994; 2000; Ramakrishnappa et al., 2005). Potential effects of PDE inhibitors in sheep reproductive activity are not well studied. In a recent study (Valasi et al., 
2012) we found that ewes that received GnRH analogue and IBMX had increased LH blood concentrations, possibly due to an enhanced pituitary response. This increase in $\mathrm{LH}$ concentrations was accompanied by higher cycling and pregnancy rate in ewes, supporting the concept that IBMX could affect follicular development in GnRH-treated ewes both directly (Ramakrishnappa et al., 2005) or through the hypothalamo-hypophyseal axis (Webb et al., 1999; Sirotkin et al., 2010b).

Furthermore, IBMX can be used in order to decrease eCG doses that are commonly given in oestrus synchronization. The objective of the present study was to evaluate effects of IBMX administration concomitantly with eCG on reproductive parameters in ewes. Moreover, the combination of different doses of eCG and IBMX are evaluated.

\section{Materials and Methods}

Two trials were carried out in 3- to 5-year-old Chios-breed cross ewes (bodyweight range: $55-65 \mathrm{~kg}$ ) in the same flock during the breeding season of two consecutive years, starting at early July. The study was carried out in the outskirts of Karditsa town in central Greece $\left(39^{\circ} 21^{\prime} 56^{\prime \prime} \mathrm{N}\right.$ and $\left.21^{\circ} 55^{\prime} 18^{\prime \prime} \mathrm{E}\right)$. All experiments were approved by the Greek Ministry of Rural Development and Food, in compliance with the E.U. directives.

\section{Trial 1}

In total, 80 ewes were allocated into one of the following groups: $\mathrm{AC}(\mathrm{n}=16), \mathrm{A} 1(\mathrm{n}=12), \mathrm{A} 2(\mathrm{n}=8)$, A3 $(n=10)$ and DC $(n=10), D 1(n=9), D 2(n=9), D 3(n$ $=6$ ). Oestruses were synchronized by intravaginal insertion of progestagen sponges (20 mg fluorogestone acetate) for 14 days. At the time of sponge removal, in ewes of groups A, a dose of 400 IU of eCG (Folligon, Merck Animal Health, Summit, USA) was i.m. administered. Concomitantly with eCG, ewes of groups A1, A2 and A3 received i.m. a $2 \mathrm{ml}$ solution containing 2.5, 5.0 and 25.0 mg IBMX (Sigma, St. Louis, USA), respectively. At the time of sponge removal, in ewes of D1, D2 and D3 groups was i.m. administered only a $2 \mathrm{ml}$ solution containing 2.5, 5.0 and $25.0 \mathrm{mg}$ IBMX, respectively. Ewes in control groups, $\mathrm{AC}$ and $\mathrm{DC}$, received an i.m. injection of $0.001 \%$ DMSO solution in PBS.

For the preparation of the injectable solution of IBMX, stock preparation was dissolved aseptically in dimethyl sulfoxide (DMSO; Sigma, St. Louis, USA) and then diluted in PBS (Sigma, St. Louis, USA); concentration of DMSO in the injectable solution was $<0.001 \%$.

Forty-eight hours after sponge removal, rams of known fertility were introduced for natural mating at a ratio of 1 ram per 10 ewes. Pregnancy diagnosis and fetal counting was performed by ultrasonography 40-45 days after mating. Number of lambs born per ewe was recorded at lambing.

Trial 2

The second trial was designed based on results of trial 1. In total, 118 ewes were allocated into one of the following groups: BC1 $(\mathrm{n}=29), \mathrm{B} 1(\mathrm{n}=30), \mathrm{BC} 2$ $(n=30)$ and B2 $(n=29)$. Oestruses were synchronized by intravaginal insertion of progestagen sponges $(20 \mathrm{mg}$ fluorogestone acetate) for 14 days. At the time of sponge removal, a dose of 200 IU of eCG was i.m. administered in $\mathrm{BC} 1$ and $\mathrm{B} 1$ groups, while a dose of $100 \mathrm{IU}$ of eCG was i.m. administered in $\mathrm{BC} 2$ and $\mathrm{B} 2$ groups. At the same time, ewes of groups B1 and B2 received a $2 \mathrm{ml}$ solution containing $2.5 \mathrm{mg}$ IBMX; while ewes in control groups $\mathrm{BC} 1$ and $\mathrm{BC} 2$ received DMSO solution in PBS. The injectable solution of IBMX was prepared as in Trial 1. Natural mating and pregnancy diagnosis were performed as in Trial 1. Number of lambs born per ewe was recorded at lambing.

\section{Statistical analysis}

All analyses were performed by a commercial statistical program (SPSS, v. 15 for Windows; SPSS Inc., Chicago, IL, USA). Statistical significance was set at $\mathrm{P}<0.05$

In both trials the following measures of reproductive performance were calculated: 'pregnancy rate' (number of ewes found pregnant by ultrasonographic examination / number of ewes mated $x$ $100)$ or 'lambing rate' (number of ewes that lambed/number of ewes mated $\times 100$ ) and 'total lambs per ewe' (number of live born and stillborn lambs / number of ewes that lambed) (Menzies, 1997; Fthenakis, 2001).

The first two measures were compared within or between groups A, D or B by chi-square test. The third measure was compared within the same groups by one-way analysis of variance and compared between A1 and D1 or B1 and B2 groups, respectively, by using the Student's $t$-test. Levene's test was used for the control of homogeneity of variances and statistical differences were estimated using Duncan's test.

\section{Results}

In both trials, no fetal losses were observed; as a result rates of pregnancy and lambing were the same.

Trial 1

Results of pregnancy or lambing rate and total lambs per ewe are presented in Table 1. In A groups, no differences were observed for pregnancy or lambing rate between groups $(\mathrm{P}>0.05)$. However, total lambs per ewe was significantly higher in A1 compared to AC $(\mathrm{P}=0.016), \mathrm{A} 2(\mathrm{P}=0.019)$ or $\mathrm{A} 3(\mathrm{P}=0.001)$. In $\mathrm{D}$ groups, no differences were evident for pregnancy or lambing rate $(\mathrm{P}>0.05)$, as well as for total lambs per ewe $(\mathrm{P}>0.05)$.

Comparisons between A and D groups revealed that pregnancy rates and lambing rates did not differ between $\mathrm{A}$ and $\mathrm{D}$ groups $(\mathrm{P}>0.05)$. Total lambs per ewe were significantly higher only in A1 compared to D1 group ( $\mathrm{P}=0.0002)$. 
Table 1. Pregnancy or lambing rate (\%) and total lambs per ewe (Mean \pm S.E.M.), in Trial 1 [groups A (AC, A1, A2 and A3: 400 I.U. eCG combined with IBMX at 2.5, 5.0 or $25 \mathrm{mg}$ for group A1, A2 or A3, respectively) and groups D (DC, D1, D2 and D3: only IBMX at 2.5, 5.0 or $25 \mathrm{mg}$ for group D1, D2 or D3, respectively)] and Trial 2 [groups B (BC1 and B1: 200 I.U. eCG combined with $2.5 \mathrm{mg}$ IBMX for B1; BC2 and B2: 100 I.U. eCG combined with 2.5 mg IBMX for B2)].

\begin{tabular}{cccc}
\hline & Group & $\begin{array}{c}\text { Pregnancy or } \\
\text { lambing rate (\%) }\end{array}$ & $\begin{array}{c}\text { Total lambs per ewe } \\
(\text { Mean } \pm \text { S.E.M.) (Min, max; } \mathrm{n})\end{array}$ \\
\hline Trial 1 & AC & $50.00(8 / 16)$ & $2.00 \pm 0.38(1,4 ; \mathrm{n}=8)^{\mathrm{b}}$ \\
& A1 & $75.00(9 / 12)$ & $3.22 \pm 0.40(2,5 ; \mathrm{n}=9)^{\mathrm{a}}$ \\
& A2 & $50.00(4 / 8)$ & $1.75 \pm 0.25(1,2 ; \mathrm{n}=4)^{\mathrm{b}}$ \\
& A3 & $60.00(6 / 10)$ & $1.33 \pm 0.21(1,2 ; \mathrm{n}=6)^{\mathrm{b}}$ \\
& & & \\
& DC & $70.00(7 / 10)$ & $1.57 \pm 0.20(1,2 ; \mathrm{n}=7)^{\mathrm{a}}$ \\
& D1 & $77.78(7 / 9)$ & $1.71 \pm 0.18(1,2 ; \mathrm{n}=7)^{\mathrm{a}}$ \\
D2 & $80.00(8 / 10)$ & $1.88 \pm 0.13(1,2 ; \mathrm{n}=8)^{\mathrm{a}}$ \\
& D3 & $83.33(5 / 6)$ & $2.20 \pm 0.49(1,4 ; \mathrm{n}=5)^{\mathrm{a}}$ \\
& & \\
BC1 & $75.86(22 / 29)$ & $1.32 \pm 0.10(1,2 ; \mathrm{n}=22)^{\mathrm{a}}$ \\
& B1 & $70.00(21 / 30)$ & $1.67 \pm 0.11(1,2 ; \mathrm{n}=21)^{\mathrm{b}}$ \\
& BC2 & $66.67(20 / 30)$ & $1.29 \pm 0.10(1,2 ; \mathrm{n}=21)^{\mathrm{a}}$ \\
B2 & $68.97(20 / 29)$ & $1.70 \pm 0.13(1,3 ; \mathrm{n}=20)^{\mathrm{b}}$ \\
\hline
\end{tabular}

${ }^{\mathrm{a}, \mathrm{b}}$ Values marked with different letter within the same group (A, D or B) differ significantly $(\mathrm{P}<0.05)$.

\section{Trial 2}

Results of pregnancy or lambing rate and total lambs per ewe are presented in Table 1. In B groups, no differences were observed for pregnancy or lambing rate between groups $(\mathrm{P}>0.05)$. However, total lambs per ewe were significantly higher in group B1 compared to $\mathrm{BC} 1(\mathrm{P}=0.025)$, as well as in group $\mathrm{B} 2$ compared to $\mathrm{BC} 2(\mathrm{P}=0.010)$.

\section{Discussion}

This is the first clinical study evaluating the effects of an IBMX inhibitor, concomitantly administered with eCG, on reproductive parameters in ewes. In trial 1 , ewes that received a dose of $400 \mathrm{IU}$ of eCG and the lower dose of IBMX (2.5 mg) presented increased total lambs per ewe in contrast to control ewes. No effects were evident in ewes receiving higher doses of IBMX (5 or $25 \mathrm{mg}$ ). Whereas, ewes that received only IBMX presented no effect on total lambs per ewe, indicating that IBMX action at ovarian level depends on gonadotrophins. Based on this result, trial 2 was designed, in order to evaluate the use of lower doses of eCG (200 or $100 \mathrm{IU})$ in combination with the lower dose of IBMX. The results in trial 2 showed that the simultaneous administration of the lower dose of IBMX and of eCG, irrespectively to dose, increased total lambs born per ewe. In both trials, no effect of treatment was observed in pregnancy or lambing rate.

In trial 1 , simultaneous administration of eCG with the lower dose of IBMX, caused significant increase in total lambs per ewe, while no effect was observed when IBMX was given alone. The significantly higher number of lambs born per ewe in ewes receiving both eCG and IBMX points out to an enhancement of eCG action when given concurrently with IBMX. Hence, it may be suggested that IBMX can enhance reproductive performance of eCG-treated ewes, findings which are in agreement with previous studies indicating that administration of synthetic PDE4 inhibitors increased number of ovulations, embryos and pups in gonadotrophin-stimulated rats (McKenna et al., 2005). In similar experiments with GnRH or gonadotrophin-treated rabbits, IBMX administration also resulted in increased number of ovulations, embryos, pregnancy and birth rates, as well as number, viability and birth bodyweight of newborns (Sirotkin et al., 2010a).

The main important finding of the present study is the significantly higher total lambs per ewe in A1 group, which received the lowest IBMX dose in conjunction with eCG, compared to other groups which received higher IBMX doses. In other studies, the effect of different doses was reported for rabbits, where a high dose of IBMX (500 $\mu \mathrm{g}$ per animal) induced an increase in total number of ovarian follicles, which was attributed to an increase in the number of secondary, but not tertiary follicles, whilst a lower dose of IBMX26 $\mu \mathrm{g}$ per animal) induced changes in progesterone blood concentration, markers of proliferation and apoptosis (Sirotkin et al., 2010b). Mechanisms of action of high doses of IBMX still need to be elucidated. A toxicity study using a PDE4 inhibitor (Losco et al., 2010) detected adverse dose related effects on ovarian function, which might also be occurring after IBMX administration.

Our previous results showed higher cycling and pregnancy rate in GnRH - IBMX - treated ewes (Valasi et al., 2012), supporting the concept that IBMX could positively affect follicular development both directly (Ramakrishnappa et al., 2005) or through the hypothalamo-hypophyseal axis (Webb et al., 1999; Sirotkin et al., 2010b). It is known that selection of dominant follicles is primarily mediated by LH and IGF-1, the latter evoking the formation of receptors for 
FSH and LH in dominant follicles thus rendering them more sensitive to LH effect (Webb et al., 1999; van den Hurk and Zhao, 2005). As it has been argued for rats treated with a selective PDE4 inhibitor, the target for its action is most likely the $\mathrm{LH}$ receptor-expressing ovarian cells (McKenna et al., 2005). Thus, it is tempting to speculate that a similar mechanism may have been involved in the present study, although a non-selective PDE inhibitor was used.

In trial 2, the concomitant administration of low doses of eCG (100 or $200 \mathrm{IU})$ and IBMX (2.5 mg) improved the number of lambs born per ewe. Thus, it may be suggested that IBMX treatment increases the number of selected and preovulatory follicles, even when low doses of eCG are administered.

In addition, in previous studies with rats, a time related effect has also been postulated (McKenna et al., 2005). According to the latter authors, long-standing PDE4 inhibition may mimic a premature LH-like response, whereas inhibition of PDE4 after hCG induced follicular maturation may mimic normal $\mathrm{LH}$ surge (McKenna et al., 2005). Based on those results, it may be proposed a synergistic action between PDE4 inhibitor and hCG in triggering ovulation.

In conclusion, the results of the present study provide evidence that IBMX, in combination with eCG, could act as an enhancer of reproductive efficiency in ewes. Use of IBMX alone did not show an enhancement of reproductive efficiency. Furthermore, IBMX can be used, at the low dose of $2.5 \mathrm{mg}$, in order to decrease eCG doses (300-400 IU) that are commonly given in oestrus synchronization, and yet improve litter size probably by increasing ovulation rate in ewes.

Further studies are in progress in order to evaluate other PDE inhibitors in combination with or without gonadotrophins for the control of sheep reproduction. Finally, research into mechanisms of PDE functional localization in reproductive tissues will provide knowledge for limiting tissue exposure and would standardize specific types and doses of PDEs inhibitors in order to improve reproductive performance.

\section{References}

Abecia JA, Forcada F, González-Bulnes A. 2012 Hormonal control of reproduction in small ruminants. Anim Reprod Sci, 130:173-179.

Abecia JA, Forcada F, González-Bulnes A. 2011. Pharmaceutical control of reproduction in sheep and goats. Vet Clin North Am Food Anim Pract, 27:67-79.

Balazi A, Sirotkin AV, Chrenek P. 2012. Activators of protein kinase $A$ and oxytocin affect rabbit reproduction. Cent Eur J Biol, 7:973-979.

Bister JL, Noël B, Perrad B, Mandiki SN, Mbayahaga J, Paquay R. 1999. Control of ovarian follicles activity in the ewe. Domest Anim Endocrinol, 17:315-328.

Conti M, Beavo J. 2007. Biochemistry and physiology of cyclic nucleotide phosphodiesterases: essential components in cyclic nucleotide signalling. Annu Rev Biochem, 76:481-511.

Deligiannis C, Valasi I, Rekkas CA, Goulas P,
Theodosiadou E, Lainas T, Amiridis GS. 2005. Synchronization of ovulation and fixed time intrauterine insemination in ewes. Reprod Domest Anim, 40:6-10.

Fthenakis GC. 2001. Effects of retention of fetal membranes on subsequent reproductive performance of dairy ewes. Theriogenology, 61:129-135.

Greco DG, Stabenfeldt GH. 2007. The endocrine system. In Cunningham, JG and Klein, BG (Eds.). Textbook of Veterinary Physiology. St Louis, USA: WB Saunders. pp. 410-427.

Levy I, Horvath A, Azevedo M, Bertollo de Alexandre R, Stratakis CA. 2011. Phosphodiesterase function and endocrine cells: links to human disease and roles in tumor development and treatment. Curr Opin Pharmacol, 11:689-697.

Losco PE, Poulet FM, Kaminska-McNamara GZ, Klein MF. 2010. Myocardial and reproductive system toxicity of SCH 351591, a selective phosphodiesterase4 inhibitor, in CD-1 mice. Toxicol Pathol, 38:568-582.

Maurel MC, Roy F, Hervé V, Bertin J, Vaiman D, Cribiu E, Manfredi E, Bouvier F, Lantier I, Boué P, Guillou F. 2003. Immune response to equine chorionic gonadotropin used for the induction of ovulation in goats and ewes. Gynecol Obstet Fertil, 31:766-769.

McKenna SD, Pietropaolo M, Tos EG, Clark A, Fischer D, Kagan D, Bao B, Chedrese PJ, Palmer S. 2005. Pharmacological inhibition of phosphodiesterase 4 triggers ovulation in follicle-stimulating hormoneprimed rats. Endocrinology, 146:208-214.

Ménchaca A, Rubianes E. 2004. New treatments associated with timed artificial insemination in small ruminants. Reprod Fertil Dev, 16:403-413.

Menzies PI. 1997. Reproductive health management problems. In Youngquist, RS (Ed.). Current therapy in large animal theriogenology. Philadelphia, USA: WB Saunders. pp. 643-649.

Ramakrishnappa N, Rajamahendran R, Lin YM, Leung PC. 2005. GnRH in non-hypothalamic reproductive tissues. Anim Reprod Sci, 88:95-113.

Rose RD, Gilchrist RB, Kelly JM, Thompson JG, Sutton-McDowall ML. 2013. Regulation of sheep oocyte maturation using cAMP modulators. Theriogenology, 79:142-148.

Sirotkin AV, Chadio S, Chrenek P, Xylouri E, Fotopouloy H. 2010a. Phosphodiesterase inhibitor 3isobutyl-methyl-xanthine stimulates reproduction in rabbit females. Theriogenology, 74: 1321-1326.

Sirotkin AV, Chrenek P, Chadio S, Xylouri E, Fotopouloy H, Makarevich AV. 2010b. Phosphodiesterase inhibitor 3-isobutyl-methyl-xanthine affects rabbit ovaries and oviduct. Eur J Pharmacol, 643:145-151.

Sirotkin AV, Makarevich AV, Gennieser HG, Kotwica J, Hetenyi L. 2000. Effect of four cGMP analogues with different mechanisms of action on hormone release by porcine ovarian granulosa cells in vitro. Exp Clin Endocrinol Diabetes, 108:214-219.

Sirotkin AV, Makarevich AV, Grosmann R. 2010c. Protein kinases and ovarian functions. J Cell Physiol, 226:37-45

Sirotkin AV, Nitray J, Kolena J, Bulla J. 1994. Cooperation between LH-RH and LH in the direct 
action on the ovary: LH-RH stimulation of $\mathrm{LH} / \mathrm{hCG}$ receptors, basal and LH-induced cAMP and cGMP release by porcine granulosa cells in vitro. Cell Signal, 6:135-140.

Valasi I, Chadio S, Papadopoulos S, Theodosiadou E, Kalogiannis D, Mavrogianni VS, Spanos S, Fthenakis GC, Amiridis GS. 2012. Effect of combined treatment of $\mathrm{GnRH}$ and non-selective inhibitor of phosphodiesterase on subsequent fertility of ewes: preliminary results. Reprod Domest Anim, 47(s5):111.

van den Hurk R, Zhao J. 2005. Formation of mammalian oocytes and their growth, differentiation and maturation within ovarian follicles. Theriogenology, 63:1717-1751.

Webb R, Campbell BK, Garverick HA, Gong JG, Gutierrez CG, Armstrong DG. 1999. Molecular mechanisms regulating follicular recruitment and selection. J Reprod Fertil Suppl, 54:33-48. 